ISSN 1518-3483

Licenciado sob uma Licença Creative Commons

\title{
A formação do professor nos cursos de licenciatura: o que dizem os professores
}

\section{Teacher education in undergraduate courses: what teachers say}
La formación del profesor en los cursos de licenciatura: lo que dicen los profesores

\section{Joana Paulin Romanowski ${ }^{[\mathrm{a}][\mathrm{b}]}$, Pura Lúcia Oliver Martins ${ }^{[a]}$, Maria Cristina Koguti $^{[a]}$, Paulo Sérgio Maniesi ${ }^{[]^{*}}$}

[a] Pontifícia Universidade Católica do Paraná (PUCPR), Curitiba, PR, Brasil

${ }^{[b]}$ Centro Universitário Internacional (UNINTER), Curitiba, PR, Brasil

\section{Resumo}

O texto aborda a formação realizada nos cursos de licenciatura a partir do que dizem os professores oriundos desses cursos, considerando a relação entre universidade e escola. Toma por base pesquisa realizada com professores da educação básica e estudantes de cursos de licenciatura, a partir do problema: quais são os indicadores dos professores da educação básica sobre sua formação e que se expressam em suas práticas docentes

JPR: Doutor, e-mail: joana.romanowski@gmail.com

PLOM: Doutor, e-mail: pura.oliver@pucpr.br

MCK: Doutoranda máxima, e-mail: cristina.k@pucpr.br

PSM: Mestre, e-mail: psmaniesi@gmail.com 
realizadas da educação básica? O objetivo é compreender a relação da universidade com a educação básica a partir de depoimentos de professores quanto à relação entre a sua prática pedagógica e a formação efetivada nos cursos de licenciatura de modo a indicar possíveis demandas para os cursos de licenciatura. A metodologia de abordagem qualitativa de pesquisa considera a investigação realizada por meio de entrevistas e questionários com professores e coordenadores da educação básica e estudantes desses cursos. A análise é baseada em Bardin (2010) e nos aportes teóricos do campo da formação docente, considerando como categorias básicas: os conhecimentos para a formação docente; a organização da prática pedagógica e a prática docente.

Palavras-chave: Cursos de licenciatura. Escola básica. Prática pedagógica.

\begin{abstract}
The text approaches the education teachers undergo in undergraduate courses from what the professors say of these courses, considering the relation between university and school. Based on a research carried out with teachers of basic education and students of undergraduate courses, it considers this problem: what are the indicators basic education teachers specify regarding their education and which of these are expressed in the teaching practices carried out by them in basic education? The objective is to understand the relations between the university and basic education based on teachers' testimony regarding the relations between their pedagogical practice and the training carried out in undergraduate courses, all in order to indicate possible demands for undergraduate courses. The qualitative research approach methodology considers the research conducted through interviews and questionnaires with teachers of basic education and students of these courses. The analysis is based on Bardin (2010) and on the theoretical contributions of the field of teacher education, considering as basic categories: the knowledge for teacher education; the organization of the pedagogical practice and the teaching practice.
\end{abstract}

Keywords: Undergraduate courses. Basic school. Pedagogical practice. 


\section{Resumen}

El texto aborda la formación realizada en los cursos de licenciatura a partir de lo que dicen los profesores oriundos de esos cursos considerando la relación universidad y escuela. Se basa en la investigación realizada con profesores de educación básica y estudiantes de cursos de licenciatura, a partir del problema: cuáles son los indicadores de los profesores de la educación básica sobre su formación y que se expresan en sus prácticas docentes realizadas de la educación básica? El objetivo es comprender la relación de la universidad con la educación básica a partir de testimonios de profesores en cuanto a la relación entre su práctica pedagógica y la formación efectuada en los cursos de licenciatura para indicar posibles demandas para los cursos de licenciatura. La metodología de abordaje cualitativo de investigación considera la investigación realizada por medio de entrevistas y cuestionarios con profesores y coordinadores de la educación básica y estudiantes de estos cursos. El análisis se basa en Bardin (2010) y en los aportes teóricos del campo de la formación docente, considerando como categorías básicas: los conocimientos para la formación docente; la organización de la práctica pedagógica y la práctica docente.

Palavras clave: Cursos de licenciatura. Escuela básica. Práctica pedagógica.

\section{Introdução}

Nas últimas décadas, inúmeras pesquisas têm indicado a formação do professor como fundamental para a promoção de mudanças na prática pedagógica realizada nas escolas de educação básica, tais como as de Azanha (2004), Nóvoa (1992), Marcelo Garcia (1999), Gatti e Barreto (2009) e André (2010). Essa perspectiva tem gerado uma constante tensão entre as instituições formadoras, as universidades, e as instituições de atuação profissional dos professores da educação básica.

A relação entre a universidade e a escola na formação de professores tem sido abordada de diferentes perspectivas, como: o papel 
da universidade na formação inicial e continuada dos professores para a educação básica; a articulação da universidade com a escola e da escola com a universidade; as parcerias entre a universidade e a escola no desenvolvimento de projetos de pesquisa-ensino; as escolas de educação básica como campo de pesquisa sobre a formação de professores; as escolas de educação básica como campo de estágio para os cursos de licenciatura realizados pelas universidades, entre outras.

Este texto focaliza a relação da universidade com a escola de educação básica a partir do que dizem os professores sobre a formação promovida nos cursos de licenciatura. Assume como base das discussões e análises geradas a partir da pesquisa "Formação inicial de professores: a relação universidade e escola nos cursos de licenciatura" realizada pelos participantes do Grupo de Pesquisa Práxis Educativa: Dimensões e Processos, do Programa de Pós-Graduação em Educação da Pontifícia Universidade Católica do Paraná.

Analisa a relação da universidade com a educação básica, expressa nos cursos de licenciatura e na pesquisa, para apontar elementos que se manisfestam no processo de realização da formação de professores. Destaca como problema principal a questão: quais são os indicadores dos professores da educação básica sobre sua formação inicial e quais se expressam em suas práticas docentes realizadas na escola? O objetivo é compreender a relação da universidade com a educação básica expressa pelos professores quanto à relação entre a sua prática pedagógica e a formação efetivada nos cursos de licenciatura, de modo a indicar possíveis demandas para os cursos de licenciatura. Tem como objetivo decorrente identificar conhecimentos pedagógicos indicados por professores da educação e coordenadores da educação básica visando contribuir com as disciplinas pedagógicas dos cursos de licenciatura.

A metodologia de pesquisa é de abordagem qualitativa e os dados foram obtidos por entrevistas e questionários semiestruturados, com a participação de 70 professores da educação básica e 15 estudantes de cursos de licenciatura que atuam como professores naquele nível de 
ensino. A coleta de dados foi feita por pesquisadores, mestrandos e doutorandos do grupo de pesquisa já referido. A análise dos dados seguiu a análise de conteúdo proposta por Bardin (2010), atendendo os passos de: pré-análise, descrição analítica e interpretação referencial.

Para as entrevistas, foi considerada uma amostragem de profissionais da educação básica baseada nos seguintes critérios: um mínimo de participantes em cada segmento (professores, coordenadores de escola e de núcleos de ensino); inclusão de professores iniciantes (um a cinco anos de exercício profissional), experientes (de cinco a 20 anos de exercício profissional) e em fim de carreira (mais de 25 anos de exercício profissional); que atuam em escolas do centro urbano e de bairros; estudantes de diferentes cursos de licenciatura.

Constituem pressupostos teórico-metodológicos da investigação: (i) a compreensão de que a prática não é dirigida pela teoria, mas esta expressa a ação prática dos sujeitos (MARTINS, 2016); (ii) a formação do professor está em constante transformação, por se situar no contexto sócio-histórico em que se realiza, o que exige a permanente investigação.

Entende-se que os conceitos e interpretações são decorrentes de análises e reinterpretações de fatos e experiências e, por mais abstratos que sejam os procedimentos de sua autointerrogação, esta deve ser remetida a um compromisso com as propriedades determinadas da evidência, conforme Thompson (2009). Contudo, esse entendimento assume a provisoriedade do conhecimento, como definido por Thompson (2009) ao afirmar que o conhecimento é sempre provisório, incompleto, seletivo e limitado, pois as questões que o pesquisador faz às evidências, interferem nas interpretações decorrentes as quais expressam, em sua base, determinados conceitos e não outros. Desse modo, novas perguntas podem ser feitas e novas evidências serão descobertas se outras premissas fundamentarem a investigação. 


\section{Os cursos de licenciatura como condição para a formação de professores para a educação básica}

A proposição da formação de professores em nível superior ocorre desde a metade do século XIX em diferentes países europeus, como na França, Inglaterra, Áustria. Ao longo do século XX, essa formação se alastra nas universidades, ainda que de modo marginal (LABAREE, 2008).

No Brasil, os cursos de licenciatura surgem a partir de 1934, e passam a ser ofertados em todo o território nacional, tanto em universidades como em faculdades. De acordo com os últimos índices estatísticos divulgados pelo Instituto Nacional de Estudos e Pesquisas Educacionais Anísio Teixeira INEP, há oferta de 4.792 cursos de licenciaturas nas universidades brasileiras, com um total de 958.069 estudantes matriculados (BRASIL, 2015).

A formação em cursos de nível superior para o professor da Educação Básica no Brasil é indicada a partir das Leis nº 4.024/61, 5.540/68, 5.692/71, que já expressavam a exigência de formação em nível superior para os anos finais do ensino fundamental e ensino médio. Essa condição lentamente caminha para sua universalização ${ }^{1}$. Em 1996, a formação dos professores da educação básica em nível superior, em média, era de 37\%, dos quais $18 \%$ atuavam na educação infantil (creche), $0,5 \%$, nas classes de alfabetização, 43,8\%, no ensino fundamental e $86,3 \%$, no ensino médio. No ano de 2006, a formação em nível superior indicava uma elevação para $58,2 \%$, em média, estando os professores distribuídos $31,7 \%$ na educação infantil (creche), 38,2\% na pré-escola, 53,8\% nas séries iniciais do ensino fundamental, 75,0\% nos anos finais do ensino fundamental e 92,4\% no ensino médio. Os últimos dados do Censo Escolar de 2016 apontam para uma média de $76 \%$ dos professores com curso de graduação, dos quais $64 \%$ estão na educação infantil (creche), 67\%, na pré-escola, 80,1\%, no ensino fundamental e 93,2\%, no ensino médio. Há, ainda, um número significativo

1 Considerando os limites deste artigo, não serão abordadas as condições em que se realiza a formação dos professores nos cursos de licenciatura. A esse respeito, ver estudos realizados por Gatti e Barreto (2009); Romanowski (2002). 
de professores com especialização (42,6\% em média), cerca de 2,0\% com mestrado e 2.606 professores com doutorado (menos de 1,0\% do total, em média) (BRASIL, Censo escolar 1997, 2007, 2017).

No entanto, inúmeros estudos apontam para situações de crise na escola e na formação de professores. De modo paradoxal, Aranha e Souza (2013, p. 71, 78), afirmam:

quanto mais falamos em crise da educação escolar, mais escolarizada se torna a nossa sociedade; [...] quanto mais expandimos a oferta do ensino escolar, maior se revela nossa dificuldade de formar professores para atendê-la. Quanto mais escolarizada se torna nossa sociedade, maior é a sensação de que a escola não corresponde ao que esperamos dela no nosso tempo.

Em relação aos processos de formação dos cursos de licenciatura, as denúncias de aligeiramento, fragilização, e desarticulação dos currículos mostram o predomínio da lógica da teoria como guia da ação. Com efeito, é princípio dominante a racionalidade técnica do processo de formação dos professores na organização pedagógica das propostas dos cursos, bem como na abordagem didática das disciplinas, como afirma Diniz-Pereira (2000). O autor pondera que a racionalidade técnica evidencia-se quando os cursos estabelecem um "conjunto de disciplinas científicas e outro de disciplinas pedagógicas, que vão fornecer as bases do processo de formação e posteriormente na sua atuação profissional. No estágio supervisionado, o futuro professor aplica tais conhecimentos e habilidades científicas e pedagógicas às situações práticas de aula" (DINIZ-PEREIRA, 2000, p. 112).

Destarte, os cursos de licenciatura, ainda que tivessem sofrido mudanças, mantêm uma perspectiva que se assemelha à abordagem e articulação do bacharelado, inclusive, algumas das disciplinas de prática profissional estão direcionadas para a formação do profissional liberal e não para a formação específica do docente ou, como indicam Terrazan et al. (2008, p. 87), para a não constituição da identidade específica das licenciaturas, pois "os perfis profissionais e os objetivos são praticamente os mesmos para Licenciatura e Bacharelado" (ROMANOWSKI; MARTINS, 2010). 
Em outro estudo, realizado por Gatti e Barreto (2009), as autoras destacam que os cursos priorizam o aprendizado das disciplinas específicas. As ementas das disciplinas cingem-se ao abordar o campo disciplinar sem articulação com a docência. Igualmente, as ementas dos estágios pouco explicitam sobre seu desenvolvimento e a prática. Ainda, a maioria dos cursos mantém uma intensificação de conhecimentos específicos voltados para a formação do pesquisador e do bacharel, sem proximidade com a escola básica. Enfim, há a continuidade de cursos engessados sem maior vinculação com a educação básica de modo a prevalecer uma formação prescritiva. De outro lado, são restritos os estudos sobre sistemas educacionais, conteúdos de ensino, saberes relacionados às tecnologias, reforçando uma formação desarticulada da educação básica.

Desse modo, reafirma-se a prerrogativa de uma formação aligeirada e precária, indicada por Gatti e Barreto (2009), Gatti (2013), Tenti Fanfani (2005), entre outros. Na mesma linha de pensamento, Imbernón e Colén (2014) dissertam que governantes de diversos países europeus afirmam que os candidatos a professores não reúnem as condições necessárias nem assumem a responsabilidade que deveriam ter.

De outra perspectiva, a formação do professor tem suscitado reflexões em torno da complexidade da prática pedagógica, pois, como afirma Azanha (2004, p. 370), a escola atual é um "novo espaço institucional, o desempenho do professor não mais pode ser pensado como uma simples questão de formação teórica de alguém que ensina”.

Fernandes e Cunha (2013, p. 54) destacam nos estudos sobre paradoxos existentes nos cursos de licenciatura as dicotomias e os antagonismos que envolvem "as relações entre sujeito e objeto, teoria e prática, conteúdo e forma, consciência e matéria, subjetividade e objetividade". As autoras, entre outras questões, ressaltam a centralidade dos discursos disciplinares universalizantes que estabelecem "a condição de visão única, tão cara à ciência moderna e, nos dias de hoje, reforçada pelos dispositivos políticos da produtividade. Trata-se de um processo de padronização, como se houvesse uma única forma de conhecimento e uma só alternativa de formação", em que se pode provocar "a cegueira 
epistemológica e valorativa, destruindo as relações entre os objetos e, nessa trajetória, eliminando as demais formas alternativas de conhecimentos" (FERNANDES; CUNHA, 2013, p. 54).

Na perspectiva de uma formação vinculada à prática pedagógica os cursos de licenciatura favorecem os processos de reflexão. As análises da prática educativa permitem a compreensão do contexto sócio-histórico, que permite uma formação crítica a partir das situações problemáticas. Entende-se que essa perspectiva é favorecida na sistematização coletiva do conhecimento, desenvolvida em quatro momentos fundamentais, intimamente relacionados, quais sejam: (i) caracterização e problematização da prática social comum aos participantes; (ii) explicitação da prática, mediatizada por um referencial teórico; (iii) compreensão da prática no nível de totalidade; (iv) elaboração de propostas de intervenção na prática (MARTINS, 2009).

Desse ponto de vista, a relação universidade-escola é fundamental. Para Veiga e Ávila (2012), o professor, ao assumir uma concepção de educação como prática social num processo lógico de emancipação, indica a necessidade de propostas formativas que privilegiem os processos de construção coletiva em que a colaboração e a cooperação permeiem o processo. Com efeito, Imbernón e Colén (2014) indicam como possibilidades de mudança abandonar os enfoques tecnológicos, funcionalistas e burocratizantes e se aproximar de um enfoque relacional, dialógico, cultural, contextual e articulado ao social, de tal envergadura que a formação docente inclua modificar as atitudes, a mentalidade e a maneira de exercer a profissão docente.

Nesse sentido, dos programas emergentes que focalizam a relação universidade-escola na formação inicial de professores, o Programa Institucional de Bolsas de Iniciação à Docência (Pibid) tem sido apontado como exitoso. Criado pelo Decreto no 7.219 (BRASIL, 2010) e fomentado pela Capes, o programa propõe a articulação entre as instituições de ensino superior e as escolas públicas de educação básica como forma de contribuir com a formação inicial de professores, e sua contribuição tem sido destacada em inúmeros estudos². Institui-se, assim, como uma

2 Foram identificados 27 artigos na base Educ@ relativos a estudos que envolvem o Pibid, em 
possibilidade de articulação entre a teoria e a prática ao longo do processo de formação inicial.

Para Gatti et al. (2014, p. 17), resultados de estudos sobre o Pibid confirmam "o êxito da parceria universidade e escola, concretizada em ações e reflexões colaborativas e no desenvolvimento de estratégias de aprendizagem, evidenciando a melhor qualificação da formação inicial dos licenciandos". Segundo a avaliação realizada pelos autores, as contribuições expressam-se para os cursos, estudantes bolsistas, professores supervisores da escola e da universidade, professores e alunos da escola básica. Assim, o Pibid "constitui-se em rara política de atenção à formação inicial dos professores para a educação básica. É um programa que desacomoda as licenciaturas e mobiliza escolas" (GATTI et al., 2014, p. 106).

Nessa conjuntura se move a pesquisa focalizada neste artigo. Reafirmamos que o propósito é compreender a relação da universidade com a educação básica a partir de depoimentos de professores quanto à relação entre a sua prática pedagógica e a formação efetivada nos cursos de licenciatura de modo a indicar possíveis demandas para os cursos de licenciatura. A seção a seguir sintetiza os resultados a partir das categorias estabelecidas no processo de organização dos dados e análise ${ }^{3}$.

\section{Relação universidade-escola: o que dizem os professores}

De modo a atender os propósitos do artigo, serão considerados os dados obtidos por meio de entrevistas com professores da escola básica e estudantes de cursos de licenciatura. O processo de análise foi feito inicialmente pela leitura flutuante da totalidade das respostas dos participantes; em seguida, com o uso do software ATLAS.ti, foi feita sua sistematização, de modo a definir categorias de análise (BARDIN, 2010). Então, foi utilizado o Excel (2007), agrupando e compondo o corpus do que dizem

consulta realizada em 31 de maio de 2017.

3 O detalhamento dos depoimentos e do próprio processo de análise está contido em Romanowski (2015). 
os professores quanto às categorias de análise relativas aos: conhecimentos para a formação docente; a organização da prática pedagógica e a prática docente. Na perspectiva epistemológica a análise incorpora os níveis de descrição e interpretação, para posteriormente chegar à compreensão em que são possíveis indicar os determinantes, as contradições em nível de totalidade (SANTOS, 2005).

\section{Conhecimentos para a formação dos professores}

Os conhecimentos são a matéria com qual estabelecemos as relações do processo de ensino e aprendizagem. São advindos da realidade social, das áreas específicas da ciência humana, das pesquisas e reflexões desenvolvidas pela humanidade nas relações práticas com a natureza, nas práticas sociais. Portanto, situados historicamente e passíveis de mudanças e transformações nas sistematizações teóricas. É com a matéria, conhecimentos, que professores e alunos estabelecem as relações entre ensino e aprendizagem. Dos conhecimentos são estabelecidos os conteúdos das aulas, nem sempre em totalidade, restringindo a matéria aos seus fragmentos. As relações estabelecidas nessa triangulação entre conhecimento, professores e alunos não são de ordem simples e direta, mas dialetizadas, contraditórias, como intensamente analisadas por Wachovicz (1991), Martins (2009), entre outros.

Dos depoimentos obtidos pelas entrevistas é possível depreender que os conteúdos ensinados aos alunos são distinguidos como fundamentais. No processo de ensino, os professores reconhecem os conteúdos como conhecimentos, em sua maioria, aprendidos e apreendidos durante os cursos de licenciatura. No entanto, alguns depoimentos dialetizam com o modo com que foram processados pelos professores formadores nos cursos de licenciatura. Isto é, esses formadores, ao centrarem o ensino na transmissão-assimilação de conteúdos, sem estabelecer relação com as experiências dos estudantes, entre as disciplinas e áreas do conhecimento 
e abordando-os descontextualizados historicamente como verdades absolutas, assumem uma relação fragmentada com a matéria.

Os depoimentos a seguir expressam essa perspectiva:

Eu acho que em primeiro lugar é o conhecimento, sem ele a gente não pode fazer nada [...] o conhecimento é uma coisa que está sempre funcionando, [...] todo docente tem que ter isso, assim também em outras profissões (Entrevista 26).

Senti muita falta de uma relação com a prática e com conteúdos mais centrados na atualidade (Entrevista 12).

Entender o momento histórico em que nos situamos, conhecer o professor com o qual trabalhamos em sua linha teórica (Entrevista 09).

Já no início do curso, como era apaixonada por literatura, me apaixonei mais ainda considerando que tive excelentes professores. [...] Ter o domínio do conteúdo (Questionário 07).

Os professores reconhecem que o conhecimento teórico associa-se ao conhecimento prático, experiencial, contextualizado e atualizado; reconhecem a historicidade do conhecimento. Como exemplo: "A prática docente exige atualização. Estar sempre em dia com os acontecimentos, buscando informações e acima de tudo ter muita criatividade para despertar o interesse da criança" (Questionário 04).

De outra perspectiva, há depoimentos que apontam a centralidade do conhecimento na experiência, desautorizando sua formação: "Baseio minhas aulas pelas minhas experiências e experiências das minhas colegas" (Questionário 02).

Desse modo, verifica-se que a relação universidade-escola envolve a atualização da abordagem das disciplinas e seus conteúdos, ou seja, a incorporação, nas disciplinas, de estudos que situam na contemporaneidade os campos de conhecimentos específicos de modo que os licenciandos possam compreender sua abrangência e seu movimento. 
Em depoimentos os professores apontam a necessidade de atualização:

Ter interesse em sempre renovar, procurar elaborar aulas criativas e interessantes, não ficar repetindo indefinidamente as mesmas aulas. Como suportar 25 anos de sala de aula fazendo sempre a mesma coisa? Impossível! Saber que sempre estamos aprendendo e que sempre precisamos melhorar nosso repertório se quisermos continuar trabalhando com alunos (Entrevista 38).

Ainda, em alguns depoimentos, está indicada a proposição de novas disciplinas que atualizem os cursos de licenciatura, ou seja, os cursos não precisam de mais do mesmo já existente. A revisão permanente dos conteúdos das disciplinas dos cursos de licenciatura é uma necessidade que se transforma em exigência, mas além disso novos assuntos e mesmo novos campos disciplinares poderiam integrar os cursos de licenciatura.

Com efeito, além dos conhecimentos sobre a matéria a ser ensinada, os depoimentos destacam a inserção de conhecimentos múltiplos sobre o processo de ensino e aprendizagem e denunciam a falta e a fragilidade de conhecimentos pedagógicos. Assim eles se expressam:

Considero importante ter uma vasta leitura sobre a aprendizagem, sobre o aluno aprendiz e sobre a didática [...] versando sobre o ensinar e o aprender (Entrevista 25).

Gostar de aprender e ensinar - saber planejar - saber pesquisar - ter humildade - saber gerenciar conflitos - saber usar as tecnologias/materiais didáticos/ livros - saber motivar/cativar - saber respeitar diferentes opiniões - reconhecer as diferenças - poderia elencar muitas outras questões, mas penso que estas são fundamentais (Entrevista 19).

[...] trabalhar com ensino da história, com imagens, filmes, debates... (Entrevista 38).

$\mathrm{Na}$ vertente de conhecimentos pedagógicos são destacados os que dizem respeito aos processos de relação interpessoal: 
[...] de relacionamento, de enxergar o outro, de quebrar com a tua arrogância, de saber que muitas vezes além de você ensinar você aprende, o aluno te ensina, e os alunos que às vezes são um desafio para nós, têm muito a nos ensinar. Esses alunos que nos mostram o quanto a educação é limitada, enquanto formadora, e que para ultrapassar isso, chegar ao que é a educação ampla, a educação da transformação, da consciência [...] (Entrevista 26).

Como destacado em outras publicações desta investigação: intensas mudanças na prática pedagógica, vinculadas ao processo de ensino e aprendizagem, ocorreram nas últimas décadas e se expressam na prática docente. Essas mudanças envolvem a concepção do processo de ensino e aprendizagem, no qual, da transmissão-assimilação, se busca uma concepção centrada na aprendizagem de professores e alunos. Essa transformação implica uma mudança profunda no processo, pois o foco deixa de ser a assimilação do conteúdo e vai para a elaboração, não sendo o conhecimento resultante o mesmo do ponto de partida. Professores e estudantes passam a dialogar com o conhecimento, questionando e, entre si, indagando, recompondo novas propostas em que ele se modifica em projetos e criações. Assim, apresenta-se uma diversificação de possibilidades para os docentes e discentes, do planejamento à avaliação (ROMANOWSKI; MARTINS; VOUSGERAU, 2017).

Em relação aos conhecimentos é fundamental considerar, a partir dos depoimentos dos professores, as possibilidades interdisciplinares e transdisciplinares na abordagem dos conteúdos. Não se trata apenas da articulação entre assuntos e áreas do conhecimento, mas da articulação com a prática, com as experiências, com os conhecimentos prévios. A defesa é de que o interdisciplinar se estabelece, também, na relação teoria e prática ao reconhecer o conhecimento prático como tal, numa perspectiva de totalidade. Isso não quer dizer que o conhecimento experiencial e prático é suficiente. Ao contrário, é ponto de partida e em sua negação torna o conhecimento teórico esvaziado de realidade. O conhecimento prático esvaziado do conhecimento teórico torna-se animista por negar a reflexão, no entanto a natureza e origem de cada um desses conhecimentos 
é preservada. É na relação entre ambos que eles se completam, para se constituírem nova unidade a ser transformada.

\section{A organização do trabalho pedagógico}

Os professores apontam a existência de situações de conflito e desafiadoras na organização de seu trabalho, entre elas a indisciplina dos alunos, a diversidade sociocultural e o processo de inclusão de alunos com dificuldades e necessidades diversas, assumindo a formação continuada como parte de seu trabalho. Nas palavras dos professores:

[...] encontramos a questão por exemplo da indisciplina (Entrevista 06).

$\mathrm{Na}$ escola que leciono, contamos com leituras e palestras que fazem parte de nossa Formação Continuada. Essas leituras nos enriquecem com dicas para facilitar o processo ensino-aprendizagem (Entrevista 12).

[...] toda diversidade de pessoas que você encontra, e saber lidar com essa diversidade dentro dos seus limites, porque você também é humano e erra. E o tempo que você precisa para formação continuada, para que você consiga se atualizar, continuar estudando (Entrevista 38).

[...] antes de atuar, fazer aquelas vistorias, se tem acesso para cadeirantes, para deficiente visual, enfim, quantos banheiros [...] mas de todo modo é muito teórico, as disciplinas, são muito descoladas da realidade, [...] se você tem um conhecimento geral do sistema de avaliação, ao longo do ano, facilita (Entrevista 42).

Assim como o processo de ensino e aprendizagem, a educação básica foi alvo de inúmeras mudanças em sua estruturação, nas últimas décadas, afetando profundamente a organização do trabalho pedagógico dos professores. Essas transformações envolveram a democratização do ensino, com acesso à escola de alunos das mais diversas culturas e grupos sociais; a expansão das escolas com horário estendido, dito período integral; o 
ingresso no ensino fundamental de crianças com seis anos, dada a extensão do ensino fundamental para nove anos; a inclusão de alunos com necessidades especiais em turmas regulares; novas formas de avaliação e promoção dos alunos; e processos diversos de registro das atividades escolares.

As transformações têm ocasionado a intensificação do trabalho docente para atendimento e realização de atividades novas, como o trabalho com esta diversidade, que requer a organização de atividades pedagógicas diferenciadas e ampliadas. São questões pouco tratadas nos cursos de formação docente.

Por seu turno, as condições do trabalho do professor são desfavoráveis para o atendimento de novas exigências educativas. Turmas numerosas trazem complicações para a efetivação de um processo de aprendizagem para todos. A escola deixou de ser seletiva, para tornar-se democrática e isso exige a condições de trabalho adequadas, o que não seria objeto estritamente relacionado à relação universidade-escola. No entanto, são situações a serem consideradas no processo de formação docente.

\section{A prática pedagógica}

Nos depoimentos dos professores e estudantes a preocupação com uma formação que contenha a prática pedagógica para ser examinada e compreendida é uma constante.

Faltou a prática assim, porque a gente teve muita teoria, mas a prática assim, os estágios assim foram muito poucos (Entrevista 19).

[...] tinha que existir um pouco mais de práticas dentro de sala de aula. Se é formação de professores, que é licenciatura para dar aula, tinha que ser trabalhado postura do professor dentro da sala, dicção dentro da sala de aula, o professor tem que empostar a voz... (Entrevista 13).

Eles não te dão subsídios para enfrentar as dificuldades que vão aparecer em sala de aula. Porque na faculdade é tudo lindo e de repente você 
chega na sala e você vai se deparando com coisas totalmente diferentes (Entrevista 09).

Os depoimentos não se referem apenas ao estar experimentando e vivenciando situações práticas, mas a conhecimentos sobre a prática, sobre as situações reais, cotidianas, casos advindos da prática. Os depoimentos não indicam que gostariam de "receitas", manuais de soluções de problemas, o que reduziria a formação a uma perspectiva de racionalidade técnica. Ao contrário, buscam envolvimento na compreensão da prática.

Considero ser importante a vinculação dos elementos teóricos com a prática concreta que acontece na escola. Considero importante entender o momento histórico em que nos situamos, conhecer o professor com o qual trabalhamos em sua linha teórica; considero importante ter uma vasta leitura sobre a aprendizagem, sobre o aluno aprendiz e sobre a didática em sua ampla concepção, versando sobre o ensinar e o aprender (Entrevista 01).

Nos depoimentos os conhecimentos sobre a prática não se restringem apenas ao conhecimento relativo à sala de aula. Apontam conhecimentos relativos à prática como um todo. Assim eles se expressam:

Também senti falta de conhecer mais a fundo o funcionamento administrativo das escolas. A função do professor na escola para além das aulas (Entrevista 12).

[...] acho que é importante você sempre repensar a sua prática docente na verdade. Porque não tem um modelo único a ser seguido, acho que tem que saber do projeto da escola, porque varia muito de lugar para lugar que você trabalha (Entrevista 20).

Nesta perspectiva, a ênfase na compreensão da escola e dos sistemas escolares carece de ampliação nos estágios que têm focalizado, geralmente, o 
"dar aulas". A profissão do professor não se restringe a ministrar aulas, pois a sala de aula é apenas uma unidade na escola e nos sistemas escolares.

\section{Considerações finais}

Como temos afirmado nos diversos artigos originados desta pesquisa, na elaboração deste estudo, as reflexões permitiram realizar um balanço da relação universidade-escola quanto aos cursos de licenciatura, ampliando e aprofundando a compreensão em torno da tensão entre essas instituições (ROMANOWSKI; MARTINS; VOUSGERAU, 2017).

O campo da formação e profissionalização docente, em sua abrangência e importância no atual contexto, impõe a articulação coletiva dos pesquisadores para avaliações, de modo a estabelecer a pauta das prioridades para os cursos de licenciatura. Isso exige colocar a pesquisa na perspectiva de contribuir para a proposição de políticas de formação, para a valorização e a profissionalização docente que respondam às demandas do atual contexto sócio-histórico, de maneira a ofertar uma escola democrática na busca da promoção de escolarização de alto nível para todos.

Neste estudo, a análise da relação da universidade com a educação básica, tendo em vista a busca de indicadores dos professores da educação básica sobre sua formação inicial expressa em suas práticas pedagógicas, reafirma a importância da interlocução desses dois polos de formação. A partir dos depoimentos dos professores quanto à relação entre a sua prática pedagógica e a formação recebida nos cursos de licenciatura foi possível levantar não apenas as demandas desses professores para os cursos de licenciatura como também a base epistemológica de suas ações e demandas, qual seja, o entendimento da teoria como expressão da prática.

Via de regra a orientação epistemológica dos cursos de licenciatura prioriza uma sólida formação teórica tendo em vista uma prática consequente. Essa concepção está na base das denúncias de aligeiramento, fragilização e desarticulação dos currículos fundados no princípio da racionalidade técnica. Por outro lado, propostas de estreitar as relações entre 
universidade e escola básica estabelecendo a relação teoria e prática ao longo do curso e não apenas nos períodos finais têm sido colocadas em discussão por grupos que trabalham com a concepção de teoria como expressão da prática e não o seu guia e também pelos professores da educação básica que, ao serem ouvidos sobre a sua formação inicial e a experiência profissional no chão da escola, reivindicam um estreitamento da teoria dos cursos de licenciatura com os problemas inerentes às escolas onde atuam, reafirmando a importância dessa relação para a formação de professores.

Ao mesmo tempo que os professores indicam os conteúdos específicos como de fundamental importância para sua prática pedagógica, eles questionam a forma como foram trabalhados pelos professores formadores nos cursos de licenciatura: priorizando o eixo da transmissão-assimilação de conteúdo. E o fazem indicando a importância que atribuem à articulação estreita desses conteúdos com os problemas da prática desenvolvida nas escolas onde atuam. Em outros termos, os professores reconhecem a historicidade do conhecimento.

Com relação ao conhecimento, o estudo mostra que os professores sinalizam um ponto fundamental que amplia a compreensão das atividades interdisciplinares e transdisciplinares na abordagem dos conteúdos. Esta vai além da articulação entre as áreas do conhecimento e valoriza a sua realização pela articulação com a prática e seus problemas, com as experiências, com as iniciativas dos professores para fazer frente a esses problemas.

Outro ponto fundamental que precisa ser considerado nos processos formativos dos professores é a implicação que a organização do trabalho na escola tem para a prática docente. As condições objetivas de trabalho do professor, que envolvem problemas com indisciplina, turmas numerosas, falta de tempo para a organização do seu trabalho, desafios com a inclusão de alunos portadores de necessidades especiais, dentre outros, interferem na prática pedagógica do professor e pouco são consideradas nos cursos de formação docente.

A precariedade da formação diante das demandas da educação básica tem sido denunciada, o que exige mudanças a partir de uma sólida formação. Formação na perspectiva do conhecimento como objeto do trabalho 
docente na promoção da escolarização, do ensino e aprendizagem a que se agrega o processo de identidade da profissão docente e do compromisso político, de modo a contribuir com a compreensão sócio-histórica da educação como inerente à liberdade humana. Assim, a formação para a compreensão da totalidade é uma meta não concretizada. O movimento de tomada de consciência dos professores sobre a profissionalidade constituída na prática da docência, de modo a colocar a mudança do estado de "determinada pelo sistema" para "determinar-se como professor", está longe de ser realizado.

A atual condição de formação inicial dos professores é: premida temporalmente por cursos de curta duração, dicotomizada entre bacharelado e licenciatura, fragilizada pela pluralidade de disciplinas, centralizada em formação técnica com foco no saber-fazer e desprovida de fundamentos para a compreensão da sociedade e das relações que são estabelecidas na contemporaneidade. Carece dos processos de formação humana e de uma sólida formação política rompendo seus limites. Há, porém, a expectativa de que a escola ainda seja um espaço de esperança.

Vivemos um tempo em que a formação de professores tem sido posta como elemento capaz de mudar o estado em que se encontra a escola. Nesse sentido, a profissionalização do professor é vista como possibilidade de ampliar o prestígio e o reconhecimento social da categoria, ao mesmo tempo que fomenta a melhoria da prática docente. Isso implica em mudanças da participação coletiva na definição das políticas educacionais para a formação, elevação da renumeração, oportunidades de acesso aos bens culturais e fortalecimento da organização da categoria. Com efeito, transformar essas condições está diretamente ligado às condições materiais de realizar o trabalho e à organização dos sistemas escolares e da própria escola.

A relação universidade-escola ultrapassa este estudo, pois se insere no tempo e espaço social que nos cerca e nos determina. De novo, temos que nos criar e gerar novas proposições que coloquem em movimento a utopia de que é possível reinventar a escola, a formação, a pesquisa, a democracia. 


\section{Referências}

ANDRÉ, M. A pesquisa sobre formação de professores: contribuições à delimitação do campo. In: DALBEN, Â. I. L. F. et al. Didática: convergências e tensões no campo da formação e do trabalho docente. Belo Horizonte: Autêntica, 2010.

ARANHA, A. V. S.; SOUZA, J. V. A. de. As licenciaturas na atualidade: nova crise? Educ. Rev., n. 50, p. 69-86, dez. 2013.

AZANHA, J. M. P. Uma reflexão sobre a formação do professor da escola básica. Educação e Pesquisa, São Paulo, v. 30, n. 2, p. 369-378, mai./ago. 2004. Disponível em: 〈http://www.scielo.br/scielo.php?script=sci_arttext\&pid=S1517〉.

BARDIN, L. Análise de conteúdo. 5. ed. Lisboa: Edições 70, 2010.

BARDIN, L. Análise de conteúdo. São Paulo: Edições 70, 2011. 229 p.

BRASIL. Ministério da Educação. Conselho Nacional de Educação. Edital n ${ }^{\circ}$ 018/2010/CAPES - PIBID Municipais e Comunitárias, 2010. Disponível em: <http://www.capes.gov.br/>. Acesso em: 5 set. 2017.

BRASIL. Sinopses Estatísticas da Educação Básica. Brasília: INEP, 2007. Disponível em: 〈http://portal.inep.gov.br/web/guest/sinopses-estatisticas-da-educacao-basica〉. Acesso em: 31 mai. 2017.

DINIZ-PEREIRA, J. E. Formação de professores: pesquisas, representações e poder. Belo Horizonte: Autêntica, 2000.

FERNANDES, C. M. B.; CUNHA, M. I. da. Formação de professores: tensão entre discursos, políticas, teorias e práticas. Rev. Inter Ação, v. 38, n. 1, p. 51-65, abr. 2013.

GATTI, B. A. (coord.); BARRETO, E. S. de S. Professores do Brasil. Brasília: UNESCO, 2009. 
GATTI, B. Educação, escola e formação de professores: políticas e impasses. Educar em Revista, Curitiba, n. 50, p. 51-67, 2013.

GATTI, B. A.; ANDRÉ, M. E. D. A.; GIMENES, N. A. S.; FERRAGUT, L. Um estudo avaliativo do Programa Institucional de Bolsa de Iniciação à Docência (Pibid). Coleção Textos FCC, São Paulo, v. 41, p. 93-112, 2014.

IMBERNÓN, F.; COLÉN, M. T. Los vaivenes de la formación inicial del professorado: Una reforma siempre inacabada. Revista Tendencias Pedagógicas, n. 25, p. 57-76, 2014.

LABAREE, D. F. An uneasy relationship: the history of teacher education in the university. In: COCHRAN-SMITH, M.; FEIMAN-NEMSER, S.; MCINTYRE, J. D. (eds.). Handbook of research on teacher education: enduring questions in changing contexts. 3rd ed. Mahwah: Lawrence Erlbaum, 2008. p. 290-306.

MARCELO GARCIA, C. Formação de Professores para uma Mudança Educativa. Porto: Porto Editora, 1999.

MARTINS, P. L. O. A Didática e as contradições da prática. 3. ed. Campinas: Papirus, 2009. 176p.

MARTINS, P. O. Pesquisa-ensino na formação inicial de professores e a interlocução com a educação Básica: princípios e metodologia. In: ROMANOWSKI, J. P.; MARTINS, P. L. O.; CARTAXO, S. R. M. (org.). Práticas de formação de professores: da Educação Básica à Educação Superior. 1. ed. Curitiba: Champagnat, 2016. v. 1, p. 01-20.

NÓVOA, A. Formação de professores e profissão docente. In: NÓVOA, A. Os professores e a sua formação. Lisboa: Instituto de Inovação Educacional, 1992. p. 15-34.

ROMANOWSKI, J. P. As licenciaturas no Brasil: um balanço das teses e dissertações dos anos 90. Tese (Doutorado em Educação) - Faculdade de Educação, São Paulo, 2002.

ROMANOWSKI, J. P. Formação inicial de professores: a relação universidade e escola nos cursos de licenciatura. Relatório de pesquisa. Curitiba: PUCPR, 2015. 
ROMANOWSKI, J. P.; MARTINS, P. L. O. Reformulações nos cursos de licenciatura: que mudanças? In: ENCONTRO NACIONAL DE DIDÁTICA E PRÁTICA DE ENSINO (ENDIPE), 15., 2010, Belo Horizonte. Convergências e tensões no campo da formação e do trabalho docente: políticas e práticas educacionais. Belo Horizonte: UFMG, 2010. v. 1.

ROMANOWSKI, J. P.; MARTINS, P. L. O.; VOUSGERAU, D. S. A relação universidadeescola nos cursos de licenciatura - demandas para a formação docente. In: REUNIÃO NACIONAL DA ANPED, 2017, São Luís. Anais... Universidade Federal do Maranhão: São Luís, 2017.

SANTOS, O. Fundamentos sociológicos da educação. Belo Horizonte: FUMEC, 2005. TENTI FANFANI, E. La Condición Docente Análisis comparado de La Argentina, Brasil, Peru y Uruguay. Buenos Aires: Siglo XXI Editores Argentina, 2005.

TERRAZAN, E. A.; DUTRA, E. F.; WINCHC, P. G.; SILVA, A. A. Configurações curriculares em cursos de licenciatura e formação identitária de professores. Rev. Diálogo Educ., Curitiba, v. 8, n. 23, p. 71-90, jan./abr. 2008.

THOMPSON, E. P. A miséria da teoria ou um planetário de erros. Trad. Waltensir Dutra. Este livro não possui copyright. Copyleft, 2009.

VEIGA, I. P. A; ÁVILA, C. D. (org.). Profissão Docente: novos sentidos, novas perspectivas. 2. ed. Campinas: Papirus, 2012.

WACHOWICZ, L. A. O método dialético na didática. Campinas: Papirus, 1991.

Recebido: 16/10/2017

Received: 10/16/2017

Recibido: 16/10/2017

Aprovado: 25/11/2017 Approved: 11/25/2017 Aprobado: 25/11/2017 